\title{
Impact of Virtual Laboratory on the Achievement of Secondary School Chemistry Students in Homogeneous and Heterogeneous Collaborative Environments
}

\author{
Amosa Isiaka Gambari, Halima Kawu, Oluwole Caleb Falode \\ Federal University of Technology, Nigeria
}

Submitted: 23.01.2017

Accepted: 13.06 .2018

Published: 16.07.2018

\begin{abstract}
The study investigated the impact of virtual laboratory on the achievements of secondary school chemistry students in homogeneous and heterogeneous collaborative settings in Minna, Niger state, Nigeria. Three hypotheses were formulated, analyzed and tested at 0.05 alpha level. Stratified sampling technique was used to select 60 Senior Secondary Class Two (SS II) Chemistry Students. The subjects were stratified along gender and ability levels. Sixty students were randomly selected from two secondary schools in Minna, Nigeria. Thirty students (male, $n=15$; female, $n=15$ ) were selected from each school. Pretest, posttest, and experimental group design was employed. Experts validated 20item multiple-choice Chemistry Achievement Test (CAT) was used for data collection. A reliability coefficient of 0.91 was obtained from the pilot testing using Kuder Richardson (KR-20). ANCOVA and Sidak post-hoc statistics were used for testing the hypotheses at 0.05 level of significance. The results showed that: (a) students in homogeneous ability grouping taught Chemistry using virtual laboratory instruction in collaborative setting performed better than their counterpart taught Chemistry in heterogeneous grouping composition; (b) female students in homogeneous group performed better than their counterparts in heterogeneous groups; (c) the higher achiever students in homogeneous groups outperformed those in heterogeneous groups. Based on these findings, it was recommended that the use of virtual laboratory instruction in homogeneous gender and ability level grouping in collaborative setting should be encouraged in teaching practical chemistry at senior secondary schools in Nigeria.
\end{abstract}

Keywords: Virtual laboratory; Cooperative group composition; Collaborative setting; Gender; Ability grouping

\section{Introduction}

In chemistry education, laboratory activities increase students' interest in the subject matters and help their learning. Practice makes students to attain a high level of conception which could results into meaningful learning. Knowledge of Practical Chemistry helps in producing skilled technicians for industry and highly competent workers for research laboratories (Josephsen \& Kristensen, 2006). It also helps students in understanding theories and chemical principles which are abstract in nature. Practical knowledge assists students to handle chemicals safely and with confidence; gain hands-on experience in using instruments and apparatus; develop scientific thinking and enthusiasm to chemistry; develop basic manipulative and problem solving skills; gain opportunities to students as investigators of the 
experimental work; identify chemical hazards and learn to assess and control risks associated with chemicals (Garcia-Luque, Ortega, Forja, and Gomez-Perra, 2004; Shin, Yoon, Lee, \& Lee, 2002). Regrettably, the performance of students in Practical Chemistry which supposed to enhance a meaningful learning is very poor in Nigeria due to lack of laboratories at schools or insufficient laboratory facilities. Therefore, hands-on practical experiments are rarely performed in some public schools in Nigeria. Thus, such experiments can be virtually done as a result of recent developments in Educational Technology.

Crucial to the actualization of educational technology goal is the usage of Information and Communication Technology (ICT) resources. Therefore, virtual laboratory environment is an aspect of Educational Technology. Virtual laboratory is a preferable alternative, or simply a supportive learning environment to real laboratories. It provides students with opportunities such as enriching their learning experiences; conducting experiments as if they were in real laboratories; and improving their experiment related skills such as manipulating materials and equipment, collecting data, completing experiment process in an interactive way (with boundless supplies), and preparing experiment reports (Subramanian \& Marsic, 2001). Researchers reported that instructions carried out with virtual laboratory significantly increase students' achievement (Dalgarno, Bishop, Adlong, \& Bedgood, 2009; Tatli \& Ayas, 2013; Yu, Brown, \& Billet, 2005). Virtual environments allow students to observe the process in more details, compared to talk-and-chalk method of the traditional classroom. In addition, virtual environments foster attention and motivation towards the course by supporting a discussion platform among partners, peers, students and teacher (Dobson, 2009; Lawrence, 2011).

Furthermore, some researchers argued that performing experiments using a virtual environment is more effective than performing experiments in real laboratories (Bayrak, Kanli \& Kandilingec, 2007; Gambari, Fagbemi, Falode \& Idris, 2013; Pyatt \& Sims, 2012; Swan \& O'Donnell, 2009; Tatli \& Ayas, 2012). Studies showed that, in traditional learning environments, there are always inconsistencies between student predictions and observations (Josephsen \& Kristensen, 2006; Kerr, Rynearson, \& Kerr, 2004). Such environments make students to be passive learners and cause them to refrain from expressing their opinions directly (Sheppard, 2006). In contrast, virtual learning environments enable learners to repeat the events several times without hesitation, or to zoom in and out, and to watch the experimental process in slow motion (Tuyuz, 2010). Virtual laboratory is applicable to collaborative learning environment.

Collaborative learning $(\mathrm{CL})$ is an educational approach to learning that involves groups of learners working together to solve a problem, complete a task, or create a product. In the submission of Vasiliou and Economides (2007), collaborative learning is a student-centered, task-based, activity-based learning approach that provides several advantages to students. It assists the students to acquire the skills of communication, interpersonal social relationship, cooperation of sharing and caring, openness, flexibility, adaptability, knowledge retention, higher-order of critical thinking, creativity, management, practicality, responsibility, trustworthiness of dependability, involvement, engagement of participation, commitment of persistency, motivation, confidence and self-efficacy. In addition, it is an educational method in which students work together in small groups towards achieving a common goal (Tatli, \& Ayas, 2012). However, they have to cooperate effectively with each other in order to achieve the common goal (Simsek \& Tsai, 1992). In collaborative learning, students can be categorized into three ability levels which include: High, medium and low (Anyanwu, Ezenwa \& Gambari, 2014). 
Upon this classification, students can be grouped based on their ability levels. Ability grouping is the practice of dividing students for instruction on the basis of their perceived capacities for learning. The opponents of ability grouping contend that ability grouping fails to benefit students because it channels poor and minority students to low tracks where they receive a lower quality of instruction than their groups, and contributes to a widening of the achievement gap. The findings on homogeneous and heterogeneous groupings have been conflicting. For instance, Anyanwu, Ezenwa and Gambari (2014) reported no significant difference among high, medium and low ability students taught using Animation with Text and those taught with Animation with narration. In another study conducted by Kuo, and Hui-Chun (2015), it was found that the homogeneous learning style groups outperformed the heterogeneous groups. In another study, Faris (2009) reported that heterogeneity factor had a negative effect on the achievement of the students. Contrarily, Slota (2011), Mulcahy (2012) and Thomas, Emily, Feng, and Jay (2014) reported no significant difference in the achievement of students in homogeneous classrooms and those in heterogeneous classroom. Similarly, Faris (2009) showed that heterogeneity factor had a negative effect on the achievement of the students. Similar to Faris result, El-Koumy (2009) reported that the heterogeneous group students demonstrated significantly greater pre-to-posttest improvement in both their nonpreferred reading style and reading comprehension than the homogeneous group students respectively. In addition, Belland, Glazewski and Ertmer (2009) which reported that heterogeneous groups held the potential to increase motivation and social confidence of special needs of learners, and helped all members of the group (average and high ability) to overcome their own challenges.

Considering the gender in ability grouping, most researchers disagree as to which type of gender pair works productively. Dalton (1990) reported that homogeneous pairs consisting of either males or females work the best. Another study claims that heterogeneous pairs (male and female) work most effectively (Yelland, 1995). When comparing homogeneous male and homogeneous female pairs in collaborative tasks, researchers have come to many different conclusions. For instance, Pritchard, McCollum, Sundal, and Colquit (2014) revealed that females in a single gender class had significantly more game involvement than females in a coeducational class. In another study by Tsai, (2012) found that female-female interaction effect is stronger than the male-male interaction effect. This implies that girls are more influenced by female peers on academic tasks. Also, the cross-gender interactions (male to female, female to male interactions) are not significant. Similarly, Takeda, and Homberg (2014) reported that underperformance by all-male groups reduced collaborative behaviors. In addition, Shi, He, and Huan (2015) concluded that single-sex lab team education is beneficial for female students. Furthermore, Pritchard, McCollum, Sundal, and Colquit (2014) revealed that females in a single gender class had significantly more game involvement than females in a coeducational class. Researchers concluded that game performance for males and females in a coeducational physical education class was the same for males and females in a single gender class. However, Sampson, Gresham, Leigh, and McCormick-Myers (2014) reported that single-gender classrooms support mixed-gender instruction for females; while males preferred single-gender classrooms, achieved better, and grew in science self-concept. Achievement gains in science were higher in the male single-gender classroom. Discourse analysis indicated that females spoke less often in the single-gender classroom and students displayed more abstract utterances in the mixed-gender classroom. Self-concept was negatively affected by single-gender instruction for females but positively for males. Finally, Moore (2015) supports 
the body of research that has shown that single-gender education is an effective strategy for all students.

Studies on homogeneous and heterogeneous ability grouping have been controversial. For instance, Poole (2008) reported that the low-ability students in heterogeneous groups read less and were interrupted more often than the other students. Cen, Ruta, Powell, Hirsch, and $\mathrm{Ng}$ (2016) reported the analysis of a high level of predictability of group performance based solely on the style and mechanics of collaboration. The finding supports the claim that heterogeneous groups with the diversity of skills and genders benefit more from collaborative learning than homogeneous groups. Similarly, Burris, Heubert, and Levin (2006) showed that probability of completion of advanced math courses increased significantly and markedly in all groups, including minority students, students of low socioeconomic status, and students at all initial ability levels. Also, the performance of initial high achievers did not differ statistically in heterogeneous classes relative to previous homogeneous grouping, and rates of participation in advanced placement calculus and test scores improved. Likewise, Kaya (2015) reported no difference between heterogeneous and homogeneous achievement groups in terms of the numbers of total questions, lower order questions or higher order questions. High-achieving students generated more overall questions and higher order questions regardless of grouping type.

From the literature reviewed so far much has not been done on the use of virtual laboratory in Chemistry especially at senior secondary school level in Nigeria. Also, comparative studies on collaborative environments are uncommon. Similarly, studies on the homogeneous and heterogeneous ability grouping in virtual laboratory environment with reciprocal peer tutoring collaborative strategy not popular in developing nations like Nigeria. Therefore, there is need to investigate the effects of virtual laboratory in homogeneous and heterogeneous in collaborative setting.

\section{Research Hypotheses}

The following hypotheses were formulated and tested at 0.05 level of significance:

(1) There is no significant difference in the achievement scores of chemistry students exposed to virtual laboratory instruction in homogeneous and heterogeneous collaborative setting.

(2) There is no significant difference in the achievement scores of chemistry students exposed to virtual laboratory instruction in homogeneous and heterogeneous collaborative setting based on gender.

(3) There is no significant difference in the achievement scores of male and female chemistry students exposed to virtual laboratory instruction in homogeneous and heterogeneous collaborative setting based on ability level.

\section{Methodology}

The study adopted a pretest, posttest, experimental group design. In this study, there are two levels of independent variable (homogeneous \& heterogeneous), three levels of ability 
grouping (high, medium and low) and two levels of gender (male and female). Both the homogeneous and heterogeneous groups were given the pretest and posttest. The groups were subjected to treatment using virtual laboratory package in collaborative setting. The independent variables in this study are the homogeneous and heterogeneous settings while the dependent variable is the achievement scores. Gender and ability levels are considered the moderating variables.

The population for this study is the entire senior secondary school chemistry students in government schools within Minna metropolis, Niger State, Nigeria. Two senior secondary schools in Minna metropolis were purposively sampled for this study based on some criteria such as: equivalence (availability of chemistry laboratories, facilities and teachers), school type (public schools), gender composition (mixed schools), ICT equipment (computer laboratories under the School Net program) and level of exposure (students and teachers exposure to the use of computer in their schools). Stratified sampling technique was used to select sample size for this study. The students were arranged into different strata based on gender (male \& female) and ability levels (high, medium \& low), then, the required number was selected from each stratum using simple random sampling technique. Students were grouped into ability levels (high, medium and low) based on their performance in the last promotion exams in chemistry. The high level students were those whose score fall within $70-100 \%$, medium level students were those whose score fall within medium quartile of $50-69 \%$, while low achievers are students whose score in chemistry examination fall within $0-49 \%$.

Sixty students were sampled for this study and assigned to homogeneous $(n=30)$ and heterogeneous $(n=30)$. Gender grouping comprised of three-member of five sub-groups totaling 15. Male $(n=15)$, Female $(n=15)$, Male Dominated $(n=15)$, and Female Dominated $(n=15)$ groups. Similarly, ability level grouping comprised of three-member of eight groups. Three homogeneous groups which include: High achievers in two sub-groups $(n=6)$, Medium achievers $(n=6)$, Low achievers $(n=9)$. Five heterogeneous groups which include: Low Dominate Medium achievers $(n=6)$, Medium Dominate High achievers $(n=15)$, Low Dominate High achievers $(n=6)$, Medium Dominate Low achievers $(n=6)$, High, Medium and Low in two subgroups $(n=6)$. The distribution of sample is shown in Table 1.

Table 1. Distribution of Sample for the Study

\begin{tabular}{|c|c|c|c|c|}
\hline Group & Gender Grouping & $\mathrm{N}$ & Achievement Grouping & $\mathrm{N}$ \\
\hline \multirow[t]{3}{*}{$\begin{array}{l}\text { School A } \\
\text { (Homogeneous) }\end{array}$} & Male & 15 & High & 6 \\
\hline & Female & 15 & Medium & 6 \\
\hline & & & Low & 9 \\
\hline \multirow{5}{*}{$\begin{array}{l}\text { School B } \\
\text { (Heterogeneous) }\end{array}$} & Male Dominated $(2 \mathrm{M}, 1 \mathrm{~F})$ & 15 & 2Low \& 1Medium & 6 \\
\hline & Female Dominated $(2 \mathrm{~F}, 1 \mathrm{M})$ & 15 & 2Medium \&1High & 15 \\
\hline & & & 2Low \& 1High & 6 \\
\hline & & & 2Medium \&1Low & 6 \\
\hline & & & 1High, 1 Medium \& 1Lou & 6 \\
\hline
\end{tabular}

Table 1 shows distribution of sample for the study. Students in each group were exposed to the same chemistry practical concepts using virtual classroom. The teams were formed 
immediately after the pretest and worked collaboratively using the same treatment for the period of four weeks.

\section{Instrumentation}

Two research instruments were developed for this study, they are: (a) Chemistry Virtual Laboratory (CVL), and (b) Chemistry Achievement Test (CAT). Chemistry Virtual Laboratory is instructional software developed for teaching and learning Chemistry at senior secondary schools. It was used as a treatment to support collaborative learning in homogeneous and heterogeneous grouping using computer as a medium. The researcher developed CVL was written in html format using Macromedia Dreamweaver 8as the overall platform. It is made of four main components which include: (a) chemistry lecture note, (b) video of chemistry practical, (c) virtual chemistry lab, and (d) Quiz. The Chemistry lecture note enables students to read the experimental procedure; Video component was recorded using digital camera and editing suite to enable students to watch the video of chemistry practical, the chemistry virtual laboratory enables the students to perform the experiment, while the Quiz section enables the students to attempt some questions related to chemistry practical. CVL consists of four topics which include: (a) Introduction to Qualitative Analysis, (b) Identification of cations using sodium hydroxide $(\mathrm{NaOH})$, (c) Identification of cations using ammonia solution $(\mathrm{NH} 4 \mathrm{OH})$, and (d) Identification of Anions using Barium chloride solution ( $\mathrm{BaCl} 2)$. Each of these topics was taught for 40-minute lesson per week.

Chemistry Achievement Test (CAT) was used for data collection in this study. It was based on the contents of CVL. CAT consists of 20-multiple choice objective items with five option (A-E). Students were required to indicate only one correct answer from the options. CAT was administered to homogeneous and heterogeneous as pretest and after reshuffled, it was administered as posttest again. Five (5) marks were awarded for each correct answer which equal to $100 \%$.

The production of the Chemistry Virtual Laboratory was effected through a team of professionals and specialists that include: (a) computer programmers, educational technology experts; chemistry teachers and lecturers.

Experts' Validation: The developed virtual laboratory package was validated by two computer programmers in order to determine the appropriateness of the package in terms of language, typography, legibility, navigation, interface, visuals/animations, functionality, packaging, and durability. Similarly, two educational technology experts were requested to validate the package in terms of its suitability for instruction, simplicity, unity among illustrations, emphasis on key concepts, color use, and text. Their comments and suggestions were used to modify the package.

Content Validation: Two qualified chemistry teachers were requested to validate the practical materials and experimental procedures contained in the treatment. They helped to ensure that the contents and Chemistry Achievement Test were derived from the subject's curriculum and suitable for SSII chemistry students. 


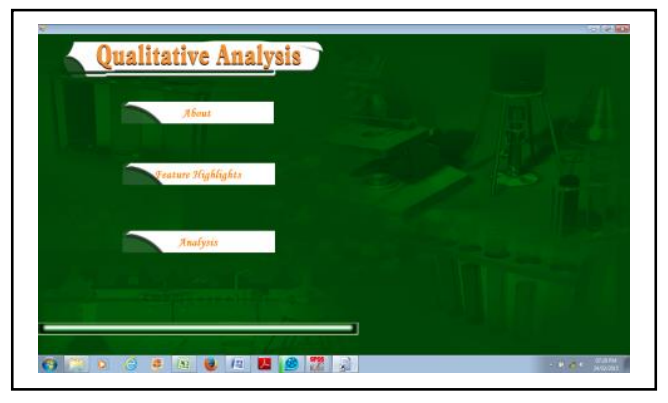

Figure 1. Homepage of CVL
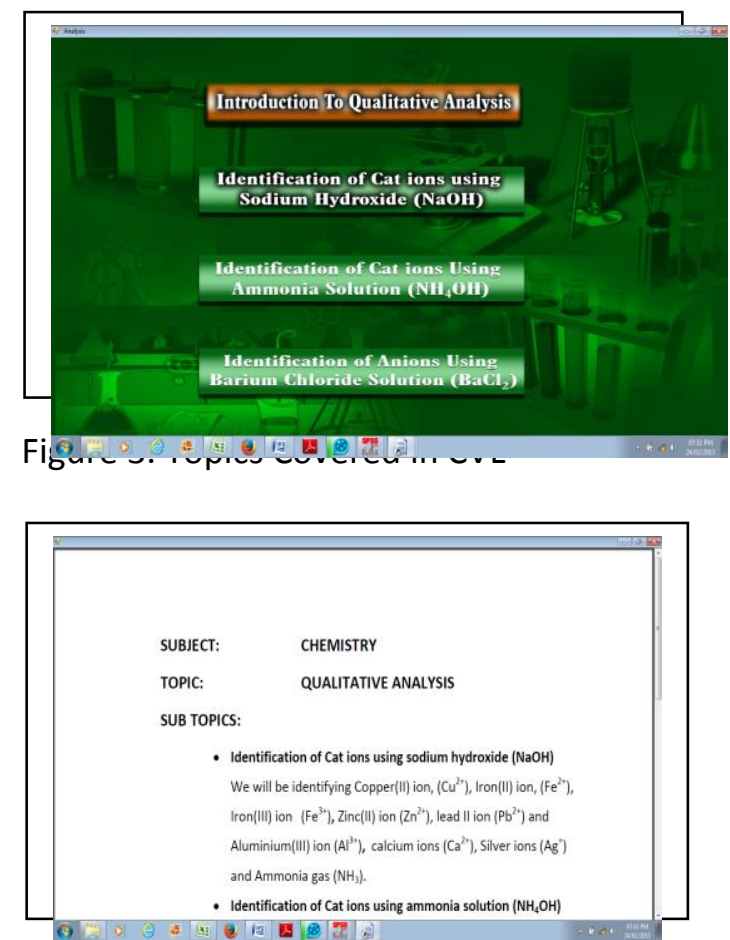

Figure 5. Note Section of CVL

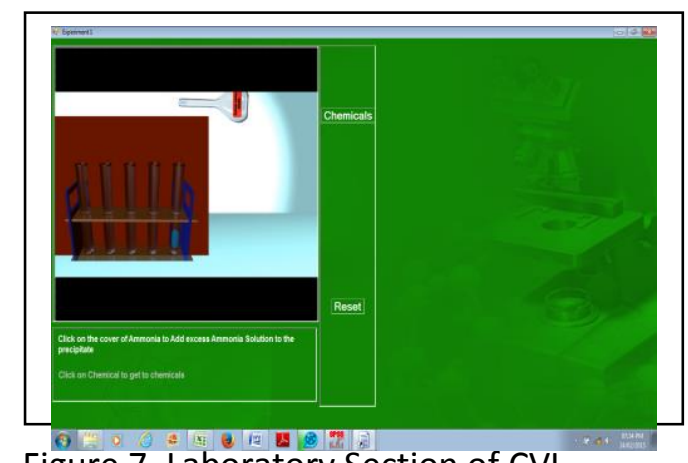

Figure 7. Laboratory Section of CVL



Figure 2. Introduction to CVL

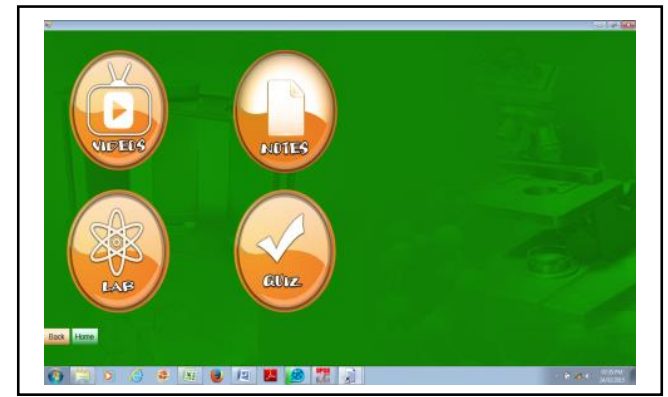

Figure 4. Components of CVL

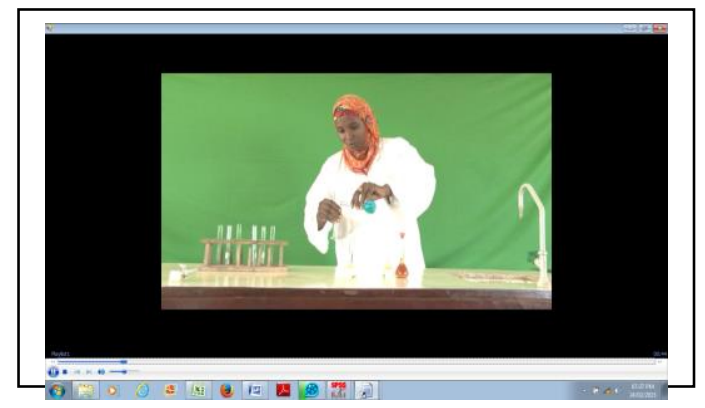

Figure 6. Video Section of CVL

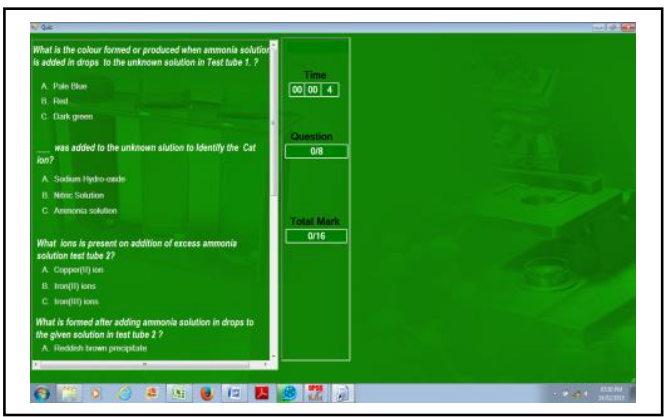

Figure 8. Quiz Section of the CVL

Validation of CAT: It was validated by two senior lecturers in Chemistry Department, Federal University of Technology, Minna, Nigeria, two chemistry teachers from secondary schools and two educational measurement and evaluation experts. These experts assess the face and content validity of the instrument in relation to secondary school chemistry class two (SSII) 
curriculum. Also, they examined CAT as a test instrument with particular reference to the: appropriateness of the content, and the extent to which the contents cover the topics they are meant to cover.

CAT was subjected to pilot testing in a selected senior secondary school in Minna metropolis, Niger state, Nigeria. The school was part of the research population but not used for the real experiment. The test instrument (CAT) was administered on 25 selected students. Reliability coefficient of 0.91 was obtained from Kuder-Richardson (KR-20). This implies that CAT had high index and was considered reliable.

Chemistry teachers of the selected secondary schools were adequately briefed, trained to ensure that they were competent in using virtual laboratory instruction. Students of those schools were also briefed and trained on collaborative learning strategies. This activity was followed by sampling the number of students required for the experiment, and team building exercise was conducted immediately. Chemistry Achievement test was administered as a pretest at the beginning of the experiment. The homogeneous and heterogeneous groups were exposed virtual chemistry lab in a collaborative setting. The learning activity involves students teaching one another in a group of three-member. Students jointly study the course materials and share the tasks. Each student takes turn and teaches another team-member. In each group, one of the group members led a discussion; another member summarized the material and ask questions, while the third member monitor the time. After four weeks of treatment, posttest was administered to both groups. The data obtained from the posttest were subjected to data analysis.

\section{Results}

Data were analyzed using Analysis of Covariance (ANCOVA) and Sidak post hoc test for testing the hypotheses. The results of the analyses are presented in the tables.

Hypothesis One: There is no significant difference in the achievement scores of chemistry students exposed to virtual laboratory instruction in homogeneous and heterogeneous collaborative setting.

Table 2. ANCOVA Results of Students Taught Chemistry Using Virtual Laboratory in Homogeneous and Heterogeneous Groups

\begin{tabular}{llllll}
\hline Source of Variation & $\begin{array}{l}\text { Sum of } \\
\text { Square }\end{array}$ & df & $\begin{array}{l}\text { Mean } \\
\text { Square }\end{array}$ & F & p-value \\
\hline Corrected Model & 394.286 & 2 & 197.143 & 3.233 & 0.047 \\
Intercept & 35387.191 & 1 & 35387.191 & 580.258 & 0.000 \\
Pretest (Covariate) & 90.536 & 1 & 90.536 & 1.480 & 0.229 \\
Group (Main Effect) & 341.551 & 1 & 341.551 & 5.583 & $0.022^{*}$ \\
Error & 3486.964 & 57 & 61.175 & & \\
Total & 330225.000 & 60 & & & \\
Corrected Total & 3881.250 & 59 & & & \\
\hline
\end{tabular}

*: Significance at $<0.05$

Table 2 shows the ANCOVA result of achievement scores of homogeneous and heterogeneous groups taught chemistry virtual laboratory in collaborative setting. The table shows that $F$ 
$(1,57)=5.583 ., p=0.022<0.05$, this result indicates that the main effect (group) was significant. On the basis of this, the hypothesis one was rejected. The results revealed that the method of groupings produce a significant effect on the posttest achievement scores of students when covariate effect (pretest) was controlled. This implies that statistically significant difference exists among the homogeneous and heterogeneous collaborative setting in favor of homogeneous group with mean score higher than heterogeneous group.

Hypothesis Two: There is no significant difference in the achievement scores of chemistry students exposed to virtual laboratory instruction in homogeneous and heterogeneous collaborative setting based on gender.

Table 3. ANCOVA Results of Posttest Scores of Gender Grouping in Homogeneous and Heterogeneous Collaborative Setting

\begin{tabular}{llllll}
\hline Source of Variation & $\begin{array}{l}\text { Sum of } \\
\text { Square }\end{array}$ & $\mathrm{df}$ & $\begin{array}{l}\text { Mean } \\
\text { Square }\end{array}$ & $\mathrm{F}$ & $\mathrm{p}$-value \\
\hline Corrected Model & 1049.163 & 4 & 262.291 & 5.094 & 0.001 \\
Intercept & 32453.755 & 1 & 32453.755 & 630.262 & 0.000 \\
Pretest (Covariate) & 17.913 & 1 & 17.913 & 0.348 & 0.558 \\
Group (Gender) & 996.429 & 4 & 996.429 & 6.450 & $0.001^{*}$ \\
Error & 2832.087 & 55 & 51.492 & & \\
Total & 330225.000 & 60 & & & \\
Corrected Total & 3881.250 & 59 & & & \\
\hline
\end{tabular}

*: Significance at $<0.05$ alpha level

Table 3 reveals the ANCOVA result of achievement scores of homogeneous and heterogeneous gender groups taught chemistry virtual laboratory in Collaborative setting. This table shows that $F(4,55)=6.450, p=0.001<0.05$, this result indicates that the gender (group) was significant. On the basis of this, the hypothesis two was rejected. The results revealed that the method of groupings produce a significant effect on the posttest achievement scores of students based on gender when covariate effect (pretest) was controlled. This implies that statistically significant difference exists among the homogeneous and heterogeneous gender grouping in collaborative setting. To further determine where the difference exists among the groups, Sidak Post hoc test was adopted.

Table 4. Sidak Analysis of Significant Difference on Mean Posttest Scores of Gender Grouping

\begin{tabular}{llrrrr}
\hline (I) & $(\mathrm{J})$ & $\begin{array}{c}\text { Mean Difference } \\
(\mathrm{I}-\mathrm{J})\end{array}$ & p-value & Lower Bound & Upper Bound \\
\hline Male & Fender & -4.00 & .567 & -11.10 & 3.10 \\
& 2M \& F & -2.00 & .971 & -9.10 & 5.10 \\
& 2F \& M & 7.00 & .055 & -.10 & 14.10 \\
Female & Male & 4.00 & .567 & -3.10 & 11.10 \\
& 2M \& F & 2.00 & .971 & -5.10 & 9.10 \\
& 2F \& M & $11.00^{*}$ & .001 & 3.90 & 18.10 \\
$2 \mathrm{M} \& \mathrm{~F}$ & Male & 2.00 & .971 & -5.10 & 9.10 \\
& Female & -2.00 & .971 & -9.10 & 5.10 \\
& 2F \& M & $9.00^{*}$ & .006 & 1.90 & 16.10 \\
$2 \mathrm{~F} \mathrm{\&} \mathrm{M}$ & Male & -7.00 & .055 & -14.10 & .10 \\
& Female & $-11.00^{*}$ & .001 & -18.10 & -3.90 \\
& 2M \& F & $-9.00^{*}$ & .006 & -16.10 & -1.90 \\
\hline
\end{tabular}


From the Sidak post hoc analysis of the four groups in Table 4, it can be deduced that significant difference was established between Female in homogeneous group and $2 \mathrm{~F} \& \mathrm{M}$ (Female Dominated) in heterogeneous group (mean diff $=11.00, p<0.05$ ) in favor of Female in homogeneous group with an upper bound of 18.10. The table also shows that there is significant difference between $2 \mathrm{M} \& \mathrm{~F}$ (Male dominated) heterogeneous group and $2 \mathrm{~F} \& \mathrm{M}$ (Female dominated) heterogeneous group (mean diff $=9.00, p<0.05$ ) with an upper bound of 16.10 in favor of $2 \mathrm{M} \& \mathrm{~F}$ (Male dominated group). Therefore, female students in homogeneous performed better than $2 \mathrm{M}$ \& $F$ (Male dominated) heterogeneous and $2 F \& M$ (Female dominated) groups, respectively.

Hypothesis Three: There is no significant difference in the achievement scores of male and female chemistry students exposed to virtual laboratory instruction in homogeneous and heterogeneous collaborative settings based on ability levels.

Table 5. ANCOVA Results of Posttest Scores of Ability Grouping in Homogeneous and Heterogeneous Collaborative Setting

\begin{tabular}{llllll}
\hline Source of Variation & Sum of Square & df & $\begin{array}{l}\text { Mean } \\
\text { Square }\end{array}$ & $F$ & P-value \\
\hline Corrected Model & $1676.780^{\mathrm{a}}$ & 8 & 209.597 & 4.849 & .000 \\
Intercept & 20156.388 & 1 & 20156.388 & 466.314 & .000 \\
Pretest (Covariate) & 1.363 & 1 & 1.363 & .032 & .860 \\
Group & 1624.045 & 7 & 232.006 & 5.367 & $.000^{*}$ \\
Error & 2204.470 & 51 & 43.225 & & \\
Total & 330225.000 & 60 & & & \\
Corrected Total & 3881.250 & 59 & & & \\
\hline
\end{tabular}

*: Significant at $<0.05$ alpha level

Table 5 shows the ANCOVA result of achievement scores of homogeneous and heterogeneous ability level groups taught chemistry virtual laboratory in collaborative setting. Table 5 reveals that $F(7,51)=5.367, p=0.000<0.05$, which indicates that the ability level grouping was significant. On the basis of this, the hypothesis three was rejected. The results revealed that the method of groupings produce a significant effect on the posttest achievement scores of students based on ability levels when covariate effect (pretest) was controlled. This implies that statistically significant difference exists among the homogeneous and heterogeneous ability levels grouping in collaborative setting. To further determine where the differences exist among the groups, Sidak post hoc test was adopted.

Table 6. Sidak Analysis of Significant Difference on Mean Posttest Scores of Students Ability Grouping

\begin{tabular}{llllll}
\hline & & Mean Difference & p-value & Lower Bound & Upper Bound \\
(I) Level & (J) Level & $(\mathrm{I}-\mathrm{J})$ & .253 & -2.35 & 22.35 \\
\hline High & Medium & 10.00 & $.000^{*}$ & 5.39 & 27.94 \\
& Low & $16.67^{*}$ & $.001^{*}$ & 5.15 & 29.85 \\
& 2L \& M & $17.50^{*}$ & .489 & -3.00 & 17.67 \\
& 1H \& 2M & 7.33 & $.012^{*}$ & 1.81 & 26.52 \\
& 1H \& 2L & $14.17^{*}$ & $.003^{*}$ & 3.48 & 28.19 \\
& 2M \& 1L & $15.83^{*}$ & .083 & -.69 & 24.02 \\
\multirow{3}{*}{ Medium } & 1H, 1M, 1L & 11.67 & .253 & -22.35 & 2.35 \\
& High & -10.00 & .810 & -4.61 & 17.94 \\
\hline
\end{tabular}




\begin{tabular}{|c|c|c|c|c|c|}
\hline & $2 L \& M$ & 7.50 & .771 & -4.85 & 19.85 \\
\hline & $1 \mathrm{H} \& 2 \mathrm{M}$ & -2.67 & 1.000 & -13.00 & 7.67 \\
\hline & $1 \mathrm{H} \& 2 \mathrm{~L}$ & 4.17 & 1.000 & -8.19 & 16.52 \\
\hline & $2 M \& 1 L$ & 5.83 & .978 & -6.52 & 18.19 \\
\hline & $1 \mathrm{H}, 1 \mathrm{M}, 1 \mathrm{~L}$ & 1.67 & 1.000 & -10.69 & 14.02 \\
\hline \multirow[t]{7}{*}{ Low } & High & $-16.67^{*}$ & $.000 *$ & -27.94 & -5.39 \\
\hline & Medium & -6.67 & .810 & -17.94 & 4.61 \\
\hline & $2 L \& M$ & .83 & 1.000 & -10.44 & 12.11 \\
\hline & $1 \mathrm{H} \& 2 \mathrm{M}$ & $-9.33^{*}$ & $.036^{*}$ & -18.35 & -.31 \\
\hline & $1 \mathrm{H} \& 2 \mathrm{~L}$ & -2.50 & 1.000 & -13.78 & 8.78 \\
\hline & $2 \mathrm{M} \& 1 \mathrm{~L}$ & -.83 & 1.000 & -12.11 & 10.44 \\
\hline & $1 \mathrm{H}, 1 \mathrm{M}, 1 \mathrm{~L}$ & -5.00 & .990 & -16.28 & 6.28 \\
\hline \multirow[t]{7}{*}{$2 L \& M$} & High & $-17.50^{*}$ & $.001^{*}$ & -29.85 & -5.15 \\
\hline & Medium & -7.50 & .771 & -19.85 & 4.85 \\
\hline & Low & -.83 & 1.000 & -12.11 & 10.44 \\
\hline & $1 H \& 2 M$ & -10.17 & .058 & -20.50 & .17 \\
\hline & $1 \mathrm{H} \& 2 \mathrm{~L}$ & -3.33 & 1.000 & -15.69 & 9.02 \\
\hline & $2 \mathrm{M} \& 1 \mathrm{~L}$ & -1.67 & 1.000 & -14.02 & 10.69 \\
\hline & $1 \mathrm{H}, 1 \mathrm{M}, 1 \mathrm{~L}$ & -5.83 & .978 & -18.19 & 6.52 \\
\hline \multirow[t]{7}{*}{$1 \mathrm{H} \& 2 \mathrm{M}$} & High & -7.33 & .489 & -17.67 & 3.00 \\
\hline & Medium & 2.67 & 1.000 & -7.67 & 13.00 \\
\hline & Low & $9.33^{*}$ & $.036^{*}$ & .31 & 18.35 \\
\hline & $2 L \& M$ & 10.17 & .058 & -.17 & 20.50 \\
\hline & $1 \mathrm{H} \& 2 \mathrm{~L}$ & 6.83 & .625 & -3.50 & 17.17 \\
\hline & $2 \mathrm{M} \& 1 \mathrm{~L}$ & 8.50 & .230 & -1.83 & 18.83 \\
\hline & $1 \mathrm{H}, 1 \mathrm{M}, 1 \mathrm{~L}$ & 4.33 & .995 & -6.00 & 14.67 \\
\hline \multirow[t]{7}{*}{$1 H \& 2 L$} & High & $-14.17^{*}$ & $.012^{*}$ & -26.52 & -1.81 \\
\hline & Medium & -4.17 & 1.000 & -16.52 & 8.19 \\
\hline & Low & 2.50 & 1.000 & -8.78 & 13.78 \\
\hline & $2 L \& M$ & 3.33 & 1.000 & -9.02 & 15.69 \\
\hline & $1 \mathrm{H} \& 2 \mathrm{M}$ & -6.83 & .625 & -17.17 & 3.50 \\
\hline & $2 M \& 1 L$ & 1.67 & 1.000 & -10.69 & 14.02 \\
\hline & $1 \mathrm{H}, 1 \mathrm{M}, 1 \mathrm{~L}$ & -2.50 & 1.000 & -14.85 & 9.85 \\
\hline \multirow[t]{7}{*}{$2 \mathrm{M} \& 1 \mathrm{~L}$} & High & $-15.83^{*}$ & $.003^{*}$ & -28.19 & -3.48 \\
\hline & Medium & -5.83 & .978 & -18.19 & 6.52 \\
\hline & Low & .83 & 1.000 & -10.44 & 12.11 \\
\hline & $2 L \& M$ & 1.67 & 1.000 & -10.69 & 14.02 \\
\hline & $1 \mathrm{H} \& 2 \mathrm{M}$ & -8.50 & .230 & -18.83 & 1.83 \\
\hline & $1 \mathrm{H} \& 2 \mathrm{~L}$ & -1.67 & 1.000 & -14.02 & 10.69 \\
\hline & $1 \mathrm{H}, 1 \mathrm{M}, 1 \mathrm{~L}$ & -4.17 & 1.000 & -16.52 & 8.19 \\
\hline
\end{tabular}

From the Sidak post hoc analysis on achievement of the eight groups in Table 6, significant difference was established between High homogeneous and $2 \mathrm{~L} \& \mathrm{M}$ (Low dominated) heterogeneous groups (mean diff $=17.50, p<0.05$ ) in favor of high in homogeneous group with an upper bound of 29.85. Similarly, significant difference was established between High and Low in homogeneous groups (mean diff $=16.67, p<0.05$ ) in favor of high in homogeneous group with an upper bound of 27.94. Also, significant difference was established between 1 High \& $2 \mathrm{M}$ (Medium dominated) in heterogeneous group and Low in homogeneous group (mean diff=9.33, $\mathrm{p}<0.05$ ) in favor of $1 \mathrm{H} \& 2 \mathrm{M}$ (Medium dominated) in heterogeneous group with an upper bound of 18.35. Finally, the table also established significant difference between $2 \mathrm{M} \& 1 \mathrm{H}$ (Medium dominated) and High in homogeneous groups (mean diff=15.83, $p<0.05$ ) in 
favor of high in homogeneous group with an upper bound of 28.19. Therefore, high achiever students in homogeneous group performed better than other ability level groupings.

\section{Summary of Findings}

- Students in homogeneous ability grouping taught Chemistry using virtual laboratory instruction in collaborative setting performed better than their counterpart taught Chemistry in heterogeneous grouping composition.

- Female students in homogeneous group performed better than their counterparts in heterogeneous groups.

- The higher achiever students in homogeneous group composition outperformed those in heterogeneous groups.

\section{Discussion}

The study revealed that students in homogeneous group taught chemistry using virtual laboratory performed better than those in heterogeneous groups. This is in agreement with the finding of Kuo, and Hui-Chun (2015) who reported that the homogeneous learning style groups outperformed the heterogeneous groups. It also agrees with that of Faris (2009) who found that heterogeneity factor had a negative effect on the achievement of the students. However, this finding contradicts that of Slota (2011), Mulcahy (2012) and Thomas, Emily; Feng, Jay (2014) who reported no significant difference in the achievement of students in homogeneous and heterogeneous classrooms. Similarly, it does not agree with that of Simsek (1993) who reported that although heterogeneous grouping was not detrimental to achievement of high ability students, it was particularly helpful for the achievement low ability students compared to their counterparts in homogeneous groups. Similarly, the results of the present study was not in agreement with the results of El-Koumy (2009) who reported that heterogeneous group students showed significantly greater pre-to-posttest improvement in both their non-preferred reading style and reading comprehension than the homogeneous group students respectively. It disagrees with that of Belland, Glazewski and Ertmer (2009) which reported that heterogeneous groups held the potential to increase motivation and social confidence of special needs of learners, and helped all members of the group (average and high ability) to overcome their challenges.

The study revealed that female in homogeneous group outperformed other in heterogeneous groups. This result is in agreement with the finding of Pritchard, McCollum, Sundal, and Colquit (2014) which revealed that females in a single gender class had significantly more game involvement than females in a coeducational class. It also agrees with that of $\mathrm{Shi}, \mathrm{He}$, and Huan (2015) who concluded that single-sex lab team education is beneficial for female students. It also agrees with that of Adodo and Agbayewa (2011) which revealed that homogeneous ability level grouping is superior for promoting students learning outcome. Similarly, the finding agrees with that of Tsai, (2012) which reported that girls are more influenced by female peers on academic. It also agrees with that of Moore (2015) which supports other researches that single-gender education is an effective strategy for all students. However, this finding is not in agreement with that of Takeda, and Homberg (2014) which result indicates underperformance by all-male groups and reduced collaborative behaviors by male students in male gender 
exception groups (i.e., groups consisting of one male student and other members being female). Also not in agreement with that of Sampson, Gresham, Leigh, and McCormick-Myers (2014) which showed that single-gender classrooms support mixed-gender instruction for females; males preferred single-gender classrooms, achieved better, and grew in science selfconcept.

The study revealed that high achiever students in homogeneous group performed better than their counterparts in other homogeneous and heterogeneous grouping. This is in agreement with that of Kaya (2015) which reported that high-achieving students generated more overall questions and higher order questions regardless of grouping type. It also agrees with that of Anyanwu, Ezenwa and Gambari (2014) that reported no significant difference among high, medium and low ability students taught using Animation with Text and those taught with Animation with narration. However, the finding of this study does not support that of Poole (2008) who reported that the low-ability students in heterogeneous groups read less and were interrupted more often than the other students. It also disagrees with that of Burris, Heubert, and Levin (2006) which revealed that probability of completion of advanced math courses increased significantly and markedly in all groups, including minority students, students of low socioeconomic status, and students at all initial ability levels. Also, the performance of initial high achievers did not differ statistically in heterogeneous classes relative to previous homogeneous grouping, and rates of participation in advanced placement calculus and test scores improved.

\section{Conclusion}

Grouping of students based on ability levels (high, medium and low) and gender (male and female) can determine the success and failure of teaching and learning process. In this study there was significant difference among high, medium and low achievers' students in heterogeneous and homogeneous groups. Those in homogeneous groups performed better than those in heterogeneous groups. However, ability grouping based on gender favor female homogeneous group than their counterparts in male homogeneous, male dominated groups, and female dominated groups respectively. Similarly, high achiever students in homogeneous group outperformed their counterparts in Medium, Low, Medium Dominated, Low Dominated, High, Medium and Low grouping respectively. This implies homogeneous grouping of students either by gender or ability levels has potentials of promoting effective collaborative learning.

\section{Recommendations}

In light of the results of this study and supporting others, the following recommendations can be made for further research and better practice:

(1) Chemistry students should be exposed to virtual laboratory in homogeneous grouping composition in collaborative setting. In other words, the use of virtual laboratory instruction in homogeneous gender and ability grouping in collaborative setting should be encouraged. This should be done by secondary school chemistry teachers to enhance effective.

(2) Female students should be grouped homogeneously when exposing to Chemistry virtual laboratory instruction in collaborative setting to enhance their academic performance. This will 
also reduce inferiority complex faced by female students in heterogeneous group. It will also eliminate gender biasness in classroom setting.

(3) Virtual laboratory instruction should be encouraged in teaching Chemistry practical to improve the performance of students irrespective of their ability levels. However, homogeneous grouping of students with different ability levels should be employed while using chemistry virtual laboratory instruction in collaborative setting.

\section{References}

Abakpa, B. O. \& lji, C. O. (2011). Effect of mastery learning approach on senior secondary school students' achievement in geometry. Journal of Science Teachers Association of Nigeria, 8(2), 24-31.

Adodo, S. O. \& Agbayewa, J. O. (2011). Effect of homogenous and heterogeneous ability grouping class teaching on student's interest, attitude and achievement in integrated science. International Journal of Psychology and Counselling, 3(3), 48-54.

Anyanwu, C. R., Ezenwa, V. I., \& Gambari, A. I. (2014). Bridging the gap between low, medium and high ability students through the use of computer-based multimedia instruction. Journal of Information, Education, Science and Technology, 1(1), 105-115.

Bayrak, B., Kanli, U., \& Kandilingec, Ş. (2007). To compare the effects of computer based learning and the laboratory based learning on students' achievement regarding electric circuits. The Turkish Online Journal of Educational Technology, 6(1), 15-24.

Burris, C. C., Heubert, J. P., \& Levin, H. M. (2006). Accelerating mathematics achievement using heterogeneous grouping. American Educational Research Journal, 43(1), 105-136.

Cen, L., Ruta, D., Powell, L., Hirsch, B. \& Ng, J. (2016). Quantitative approach to collaborative learning: Performance prediction, individual assessment, and group composition. International Journal of Computer-Supported Collaborative Learning, 11(2), 187-225.

Cohen, E. (1994). Designing group work: Strategies for the heterogeneous classroom. New York: Teachers College Press.

Dalgarno, B., Bishop, A. G., Adlong, W., \& Bedgood D. R. (2009). Effectiveness of a virtual laboratory as a preparatory resource for distance education chemistry students, Computers \& Education, 53(3), 853-865.

Dalton, D. (1990). The effects of cooperative learning strategies on achievement and attitudes during interactive video. Journal of Computer-Based Instruction, 17, 8-16.

Dillenbourg, P., Baker, M., Blay, A., \& O'Malley, C. (1996). The evolution of research on collaborative learning. In H. Spada \& P. Reimann (Eds), Learning in human and machines. Oxford: Elsevier.

Dobson, J. (2009). Evaluation of the virtual physiology of exercise laboratory program. Advances in Physiology Education, 33, 335-342.

El-Koumy, A. A. (2009). The effects of homogeneous versus heterogeneous reading-style grouping on EFL students' non-preferred reading style and reading comprehension. Retrieved on 22 January 2017 from https://files.eric.ed.gov/fulltext/ED509192.pdf 
Emily E. \& Susie J. (2006). Gender and sex: A sample of definitions. Retrieved on 15 May 2007 from http://www.genderequality..ac.ukbooks/students02014

Faris, A. O. (2009). The impact of homogeneous vs. heterogeneous collaborative learning groups in multicultural classes on the achievement and attitudes of nine graders towards learning science. Retrieved on 22 January 2017 from https://eric.ed.gov/?id= ED504109

Felder M., Felder, N., Mauney, M., Hamrin, E., \& Dietz, J. (1995). A longitudinal study of engineering student performance and retention: Gender differences in student performance and attitudes. Journal of Engineering Education, 84(2), 151.

Gambari, A. I., Falode, O. C., Fagbemi, P. O. \& Idris, B. (2013). Efficacy of virtual laboratory on the achievement and attitude of secondary school students in physics practical. Journal of Research in Curriculum, 9(1), 9-20.

Garcia-Luque, E., Ortega, T., Forja, J. M., \& Gomez-Perra, A. (2004). Using a laboratory simulator in the teaching and study of chemical processes in estuarine system. Computer Education, 43(1-2), 81-90.

Gamoran, A. \& Berends, M. (1987). The effects of stratification in secondary schools: Synthesis of survey and ethnographic research. Review of Educational Research, 57(4), 415-435.

Hafner, W. \& Ellis, T. J. (2004, January). Project-based, asynchronous collaborative learning. Paper presented at the 37th Hawaii International Conference on System Sciences. Big Island, $\mathrm{HI}$.

Hooper, S. \& Hannafin, M. J. (2006). Cooperative CBI: The effects of heterogeneous versus homogeneous grouping on the learning of progressively complex concepts. Journal of Educational Computing Research, 4, 413-424.

Johnson, D. W., Johnson, R. T., \& Stanne, M. B. (2000). Cooperative learning methods: A metaanalysis. Minneapolis, Minnesota: University of Minnesota.

Josephsen, L. \& Kristensen, A. (2006), Simulation of laboratory assignments to support students' learning of introductory inorganic chemistry. Chemistry Education Research and Practice, 7(4), 266-279.

Kaya, S. (2015). The effect of the type of achievement grouping on students' question generation in science. Australian Educational Researcher, 42(4), 429-441.

Kerr, M. S., Rynearson, K., \& Kerr, M. C. (2004).Innovative educational practice: using virtual labs in the secondary classroom, The Journal of Educators Online, 1(1), 1-9.

Kuo, Y., Chu, H., \& Huang, C. (2015). A learning style-based grouping collaborative learning approach to improve EFL students' performance in English courses. Educational Technology \& Society, 18(2), 284-298.

Kulik, C. L. (1985). Effects of inter-class ability grouping on achievement and self Esteem. Paper Presented at the Annual Convention of the American Psychological Association (93rd), Los Angeles, California. Retrieved on 15 May 2007 from https://eric.ed.gov/?id= ED263492

Melser, N. A. (1999). Gifted students and cooperative learning: A study of grouping strategies. Roeper Review, 21(4), 315-321. 
Moore, S. M. B. (2015). School administrators' and teachers' perceptions of single-gender classrooms in coeducational public middle schools within South Carolina (Unpublished doctoral dissertation). Gardner-Webb University.

Mulcahy, R. S. (2012). The effects of experience grouping on achievement, satisfaction, and problem-solving discourse in professional technical training. Educational Technology Research and Development, 60(1), 15-29.

National Examination Council (NECO, 2008-2013). May/June chief examiner's report. Minna, Nigeria: NECO.

Njoku, Z. C. (2007). Comparison of students' achievement in the three categories of questions in SSCE practical chemistry examination. Journal of the Science Teachers Association of Nigeria, 42(1\&2), 67-72.

Obrentz, S. B. (2012). Predictors of science success: The impact of motivation and learning strategies on college chemistry performance (Unpublished doctoral dissertation). Department of Educational Psychology and Special Education, Georgia State University.

Okebukola, P. A. O. (2006). Students' performance in practical: A study of some related factors. Journal of Research in Science Teaching, 24(2), 119-126.

Pritchard, T., McCollum, S., Sundal, J., \& Colquit, G. (2014). Effect of the sport education tactical model on coeducational and single gender game performance. Physical Educator, 71(1). Retrieved on 22 January 2017 from https://eric.ed.gov/?id=EJ1059778

Poole, D. (2008). Interactional differentiation in the mixed-ability group: A situated view of two struggling readers. Reading Research Quarterly, 43(3), 228-250

Pyatt, K. \& Sims, R. (2012). Virtual and physical experimentation in inquiry-based sciencelabs: Attitudes, performance and access. Journal of Science Education and Technology, 21(1), 133-147.

Rhea, M. (2010). The power of collaborative learning for associations. Retrieved on 22 January 2017 from http://www.asaecenter.org/Resources/ANowDetail.cfm?ltemNumber

Rosser, S. V. (1997). Re-engineering female friendly science. New York: Columbia Teachers College Press.

Sampson, P. M., Gresham, G., Leigh, M., \& McCormick-Myers, D. (2014). Do you want singlegender science classrooms in your middle schools? Teacher Education and Practice, 27(1), 190-202.

Sandler, B. R., Silverberg, L. A., \& Hall, R. M. (1996). The chilly classroom climate: A guide to improve the education of women. Washington, DC: National Association for Women in Education.

Sheppard, K. (2006). High school students' understanding of titrations and related acid-base phenomena. Chemistry Education Research and Practice, 7(1), 32-45.

Shi, W., He, X., Wang, Y., \& Huan, W. (2015). Effects of lab group sex composition on physics learning. EURASIA Journal of Mathematics, Science \& Technology Education, 11(1), 8792.

Shin, D., Yoon, E. S., Park, S. J., \& Lee, E. S. (2002). Web-based interactive virtual laboratory system for unit operations and process systems engineering education. Computers and Chemical Engineering, 24, 1381-1385. 
Simsek, A. (1993). The effects of learner control and group composition on student performance, interaction, and attitudes during computer-based cooperative learning (Unpublished doctoral dissertation). University of Minnesota, Twin Cities.

Simsek, A. \& Tsai, B. (1992). The impact of cooperative group composition on student performance and attitudes during interactive videodisc instruction. Journal of Computer-Based Instruction, 19(3), 86-91.

Slavin, R. E. (1995). Cooperative learning: Theory, research, and practice (2nd ed.). Boston, MA: Allyn \& Bacon.

Swan, A. \& O'Donnell, A. (2009). The contribution of a virtual biology laboratory to college students' learning. Innovations in Education and Teaching International, 46, 405-419.

Subramanian, R. \& Marsic, I. (2001). VIBE: Virtual biology experiments. Retrieved on 10 August 2010 from http://www.hkwebsym.org.hk/(2001)/E4-track/vibe.pdf

Tatli, Z. \& Ayas, A. (2013). Virtual chemistry laboratory: Effect of constructivist learning environment. Turkish Online Journal of Distance Education, 13(1), 183-199.

Takeda, S. \& Homberg, F. (2014). The effects of gender on group work process and achievement: An analysis through self- and peer-assessment. British Educational Research Journal, 40(2), 373-396.

Thomas, E. \& Feng, J. (2014, October). Effects of ability grouping on math achievement of third grade students. Paper presented at the Annual Conference of Georgia Educational Research. Savannah, GA.

Tsai, C. (2012). Peer effects on academic cheating among high school students in Taiwan. Asia Pacific Education Review, 13(1), 147-155.

Tuyuz, C. (2010). The effects of virtual laboratory on students' achievement and attitudes in chemistry. International Online Journal of Sciences, 2(1), 37-53.

Vasiliou, A. \& Economides, A. A. (2007). Mobile collaborative learning using multicast MANETs. International Journal of Mobile Communications, 5(4), 423-444.

Webb, N. M. (1991). Sex differences in interaction and achievement in cooperative small groups. Journal of Educational Psychology. 76(1), 33-44. Retrieved on 9 July 2007 from http://psycnet. apa.org/index.cfm?fa=buy.optionToBuy\&id=1984-16230

Yelland, N. (1995). Collaboration and learning with LOGO: Does gender make a difference. Proceedings of CSCL'95. Retrieved on 15 May 2007 from http://wwwcscl95.indiana.edu /cscl95/yelland.html

Yu, J. Q., Brown, D. J., \& Billet, E. E. (2005). Development of virtual laboratory experiment for biology. European Journal of Open, Distance and E-Learning, 1-14. Retrieved on 9 July 2007 from http://www.eurodl.org/materials.htm

Yusuf, A. (2004). Effects of cooperative and competitive instructional strategies on junior secondary school students' performance in social studies, in Ilorin, Nigeria (Unpublished doctoral dissertation). Department of Curriculum Studies and Educational Technology, University of llorin, Nigeria. 
CONTEMPORARY EDUCATIONAL TECHNOLOGY, 2018, 9(3), 246-263

https://doi.org/10.30935/cet.444108

Yusuf, M. O. (1997). Effects of videotape and slide-tape instructions on junior secondary students' performance in social studies (Unpublished doctoral dissertation). Department of Curriculum Studies and Educational Technology, University of Ilorin, Nigeria.

Correspondence: Amosa Isiaka Gambari, Associate Professor and Deputy Director of the Centre for Open Distance and e-Learning, Federal University of Technology, Minna, Nigeria 